\title{
Barefoot Tutors? Navigating the Barriers between student, university and field in social work education
}

\section{Gary Clapton $^{1}$ and Ruth Forbes ${ }^{2}$}

\begin{abstract}
Summary: Bridging the gap between theory and practice has long been a challenge for social work students. Facilitating this process has also taxed practice teachers and academic tutors. In 2004, the University of Edinburgh, in partnership with Glasgow Caledonian University undertook a pilot project testing and researching a change in the traditional tutor role with a view to enhancing students' integration of learning during the practicum. This paper outlines the background to and the activity and findings of the project. Then, drawing upon a discussion of the interface between psychodynamic theories and theories of education, we explore some ideas that have begun to emerge that have the possibility of enhancing the tutor role in student integration of learning.
\end{abstract}

Keywords: integration of learning; student; tutor;relationship

1. Senior Lecturer in Social Work

2. Social Work Tutor

Address for Correspondence: School of Social and Political Studies, University of Edinburgh, 2.28 Chrystal Macmillan Building 15a George Square Edinburgh EH8 9LD. Gary.Clapton@ed.ac.uk

Date of publication: 30th November 2009

5 J. of Practice Teaching \& Learning 9(1) 2009, pp.5-19. DOI: 10.1921/146066909X481420. (C) wEb 


\section{Introduction}

The challenge of navigating the divisions between university and field emerges via identifiable tensions between the objectives of higher education concentrating as they do on academic standards and the demands of professional training which emphasise practice readiness (Cree \& MacCauley, 2000). This paper works from the assumption that such divisions create barriers which make the integration of learning difficult for all students. We will explore key issues in relation to the integration of learning as it affects students undertaking education in social work. Our analysis is located in the experiences of a Scottish university project which aimed to bridge the barriers and gaps between the classroom and the field. The object having been not so much to abolish the distinctions between the two, but to 'join up' a hitherto fragmented learning process. The paper will set the subject in context and outline the learning from our research project, then advance some ideas that have since emerged concerning the interpersonal dynamics of the relationship between student and academic (henceforth tutor). Theoretical underpinnings for our analysis will come from Paulo Friere's ideas about making education relevant and we will also draw upon specific insights from psychodynamic theories.

\section{The Context}

Social work education in Scotland has undergone major structural and philosophical change in recent years. A new four-year Honours degree (introduced in 2004) has accompanied the drive for a 'competent and confident workforce which can work authoritatively alongside other professionals' (Scottish Executive, 2003). Autonomy and accountability are promoted alongside the protection of the public via registration through a regulatory body, the Scottish Social Services Council. The requirement for registration has been extended to include student social workers. The commitment to practice learning within the new degree has been expanded and all students must spend a minimum of 200 days in practice learning over the course of their studies. This increase reflects the belief that significant learning occurs in the "real world' of practice.

6 J. of Practice Teaching \& Learning 9(1) 2009, pp.5-19. DOI: 10.1921/146066909X481420. @ w\&-b 
Not all of this has been experienced positively. Social Work in the UK has been under pressure, feeling both the push to develop professionally and the pull of the contemporary employment context, constructed and influenced as it is via a managerialised, regulated and procedurally driven culture (Stalker, 2003; Scottish Executive, 2006). A consequence of these pressures has been the emergence of an antiintellectual, academia-suspicious practice posture, where theory is both questioned and may even be deemed irrelevant (Fook, 2002). Often demands for organisational efficiency may take precedence over deeper professional development. Research conducted over the last 10 years has identified that employers who take on new social work graduates have experienced some disappointment in their seeming inability to 'hit the ground running'; and newly qualified workers may similarly feel insecure, because they do not yet feel fully ready to practise (Marsh $\&$ Triseliotis, 1996; Rea, 1997).

Students' difficulty with integrating their learning has been perceived as one of the major features of this area of dissatisfaction. They often find it difficult to make connections between their theoretical, academic learning and their learning on placement. This can lead to frustration, as students attempt to achieve what might appear to be an abstract and largely unattainable task of 'relating theory to practice' (Parker, 2005; Coulshed \& Orme, 2006). A collective sigh of despair can be heard from either end of the assessment table as student, practice teacher and tutor experience the difficulty in achieving this goal of integrating learning: with all parties perhaps struggling to create common ground. Thus, for instance, the tutor's placement visit, whilst potentially a fertile area for shared discourse, can suffer from a disappointing lack of clarity of purpose.

So, the realities of both the student placement and the employment context create a challenge for social work educators. How does the student achieve adequate practice competence which builds upon a unity of field and class? In a phrase, how can they best achieve integrated learning for practice?

J. of Practice Teaching \& Learning 9(1) 2009, pp.5-19. DOI: 10.1921/146066909X481420. @ wEb 


\section{Learning from the Research Project}

Between November 2003 and July 2005, the University of Edinburgh in partnership with Glasgow Caledonian University took part in a study of Integration of Learning, commissioned by the Scottish Institute for Excellence in Social Work Education (SIESWE). Three methods were employed to examine the integration of learning to practice - firstly a postal audit of social work practitioners, educators and students' views. Secondly, a review of relevant literature across the fields of education and health professions (Clapton \& Cree, 2004) and lastly a demonstration project which sought to trial a new approach to the integration of learning for practice (Clapton et al, 2006).

The outcomes of the practice audit were clear. The majority view of the respondents indicated that there was an unhelpful gap between the academic and practice components of the student social workers' programme. The challenges for students in effectively integrating their learning with their social work practice were summed up by the concept of two separate worlds, classroom and field, with academia (theory) and the 'real world' (practice) failing to relate effectively or meaningfully (Clapton et al., 2006). Whilst steps had been taken to bridge this gap via the involvement of practitioners in teaching and delivering certain aspects of the social work programme, there was little evidence of academics being actively involved in the practice aspects of their students' training. Lecturers and tutors were found to have little contact with the field during their students' placements and when tutor visits to students on practice learning were discussed at all, they were memorably described as being 'often perfunctory' (Clapton \& Cree, 2004).

The literature review complemented our audit's findings and furthermore demonstrated a scarcity of attention to the role of the tutor in students' practice learning: 'students have relatively little contact with tutors on placement (Watson et al., 2002, p.13), or none at all, in the case of Australian academics (Cooper et al., 1999). The review found some pointers regarding the importance of academics' involvement in such a core learning process. Shardlow and Doel importantly state that

when taken together, class and placement learning have, by custom and experience, proved to be an effective method of promoting learning about social work practice. (1996, p.6)

8 J. of Practice Teaching \& Learning 9(1) 2009, pp.5-19. DOI: 10.1921/146066909X481420. @ wEb 
The third strand of our work was an experiment relating to placements that ran between April 2004 and December 2004, the rationale for which emerged from the growing awareness that academics were absent from such an important time in student integration of learning. The overall aim was to road test an idea for bridging the gap between theory and practice and thus improving students' integration of learning. We use here the phrase 'integration of learning' in preference to the terms 'application of theory to practice' or 'transfer of learning'. The detail of the terminology is significant. The notion of applying theory to practice implicitly suggests that practice is passive, patiently awaiting the affirmation of applied knowledge. Likewise the term 'transfer of learning' suggests that the application of learning is a linear, one-way process. Both terms mirror Freire's 'banking concept', in which he argues that traditional education operates by depositing knowledge into the passive learner through a one-way process based upon an expert/novice model (Freire, 1972). In contrast, 'integration of learning' implies the concept of praxis: that is, active and dynamic connectedness, activity and mutual reciprocity between theory and practice, between learning and doing. But exactly how did we propose to achieve such praxis in students' learning?

We decided to explore how we might use tutors differently to find out whether their active involvement in students' practice placements could enhance the integration of learning. Students were clustered in groups of six to eight and sent out together to practice agencies. Tutors carrying the role of 'academic advisers' ( a term defined for the purposes of this project) were attached to each cluster and worked in the field with this group for one day per week for the duration of the three-month placement. Each academic adviser negotiated their own particular involvement in the field setting rather than having a firm 'blue-print' to follow, with the understanding that traditional placement monitoring and assessment meetings took place alongside evolving developmental opportunities (in conventional practice learning opportunities, tutors usually visit twice over the course of a placement to check progress and ensure that standards are being met). Because every practice setting was different, and each grouping of students unique, a range of varied and rich involvements was created. The benefits and analysis of the entire project have since been written up (Clapton et al., 2008; Clapton \& Daly, 2007).

Although a relatively recent initiative, it is easy to forget the initial

9 J. of Practice Teaching \& Learning 9(1) 2009, pp.5-19. DOI: 10.1921/146066909X481420. @ wEb 
excitement and challenge felt by those of us who acted as academic advisers as we set out on this venture. We accompanied our students into the unknown of their practice settings and shared the newness of the location, experienced self-questioning with regard to role and felt varying degrees of being de-skilled as we moved from the relative safety of our 'ivory towers'. We became 'barefoot' as we stepped into the world of new learning experiences alongside our tutees, and worked with our students and practice colleagues with an immediacy which is just not possible within the traditional form of contact. We took part in processing and supervising students' practice learning and we helped clarify university procedures and documentation as these arose. Crucially, we actively worked with the students in supporting the integration of their learning from a basis of having direct experience of the detail of such learning and from being included in the evolving processing of their current practice. We came to know our students better than previously and they viewed us as relevant players in their practice experience. As first placement students, they viewed our involvement as natural and our reciprocal working relationship with our practice colleagues practically demonstrated a unified approach - a physical embodiment, so to speak, of the unity of theory and practice. The two worlds of practice and academia engaged effectively as academic advisors contributed not only to student learning but also to the agencies' continuous professional development initiatives. Academic advisors enjoyed this new proximity to practice, a participation that refreshed their practice and agency awareness. Ultimately all parties benefited from enhanced working relationships with the possibility of research opportunities also emerging from this dialogue (Clapton et al., 2008).

\section{Ongoing developments}

Since the ending of our research project, we have sought to keep alive our learning in two specific ways. Firstly, we have continued to read, think and write about integration of learning, as this paper will go on to discuss. Secondly, we have worked to embed the gains of the project in our day-to-day practice at the University of Edinburgh. It is fair to say that some faculty colleagues have expressed concerns about the

10 J. of Practice Teaching \& Learning 9(1) 2009, pp.5-19. DOI: 10.1921/146066909X481420. @ w\&-b 
potential increase in workload that such a development might entail. Nevertheless, we have gone so far as to make a commitment that all first practicum students will go out to practice agencies in groups, with the active and regular involvement of a tutor who is attached to the agency.

We have said that we have continued, through reading and writing, to develop our understandings of the process in which we have been engaged. Some of this exploration has been theoretical in nature; at times, it has been rooted in skills and practice. What our experiences have taught us is that the challenge of integration of learning for practice is eased by navigating the barriers between academia and practice with flexibility and imagination. We now offer some thoughts that build on the notion of refreshing tutor and academic engagement with the student learning experience and process.

\section{The role of the student-tutor interpersonal dynamic in the integration of student learning.}

Incoming social work students frequently search for 'hard' knowledge. Having assimilated society's anxieties and expectations and being aware of the ultimate challenge of the job, they yearn for certainties and assurances about what is 'right'. Casting themselves as ready recipients of a 'banking' process, students can initially be unnerved by an approach which seeks to place them at the centre of their own learning. Why is this? Is it is as result of previous teaching cultures? Is it because of a confusion of intent? Are we aiming to train or educate social work students? What are our fundamental aspirations/objectives? To 'train', smacks of a competency-based, standardised, definitive process of learning. In contrast, 'education' suggests the opportunity to develop an independent practitioner, one who holds an internalised professional persona with integrated skills, knowledge and abilities: the capacity-built practitioner who might hit the ground thinking as well as running. The incoming student learns to live with or overcome such anxiety as part of a wider transition from pupil to adult learner (Baxter and King, 2004) yet it is arbitrary whether the tutor/student relationship helps in the process (Clapton et al., 2006; Clapton \& Cree, 2004; Watson and West, 2003). Certainly, we can find little in the literature about the way that the tutor and student relationship can be

11 J. of Practice Teaching \& Learning 9(1) 2009, pp.5-19. DOI: 10.1921/146066909X481420. @ wE-b 
useful in helping the student shift to the status of adult learner. Recently, however, insights from attachment theory have usefully been employed in considering ways of advancing student learning within the context of the field work educator/student relationship (Bennet \& Saks, 2006). We too have thought along such lines - in our attention to the importance of the university based tutor-student relationship.

Thinking more deeply about our experiment in having academics working in close proximity to students on placements, we have become increasingly aware of the potential centrality of the tutor-student relationship in students' learning. In this case, evidence from the real world is incontrovertible. Many successful people - practitioners, academics, artists, business leaders, politicians etc - when asked about formative influences, regularly point to one encounter or one person who played a pivotal role in their formal education. The poet Ted Hughes seems to capture this:

... I began to write rhythmical poems, long sagas in Kiplingesque rhythms. I started showing them to my English teacher... I suppose I was fourteen, fifteen. I was sensitive, of course, to any bit of recognition of anything in my writing. I remember her - probably groping to say something encouraging - pointing to one phrase saying, This is really interesting. Then she said, 'It's real poetry'. I immediately pricked up my ears. That moment still seems the crucial one. (Gourevitch, 2008, p. 273)

In focusing upon the under-theorised tutor-student dynamic, we believe that therapeutic concepts have much to offer. The viability of the connection between education and therapy can be traced back to the Frankfurt School of the 1920s which combined Marxism and psychoanalysis, political activity with individual psychology and led ultimately to the creation of critical theory as developed by Eric Fromm (Kellner, 1989). Freire's idea of 'working alongside' and Buber's views on 'the space between' (Buber, 1958; Friere, 1972) further inform such exploration This is not to suggest that we should emulate the therapistclient relationship in our contact with students, Watson and West (2003) have already drawn attention to the potential for the abuse of power in the tutor- student relationship. Rather, we seek to identify transferable material that may constructively influence a working connectedness between tutor and student.

The work of Carl Rogers is central here. Rogers contributed to and

12 J. of Practice Teaching \& Learning 9(1) 2009, pp.5-19. DOI: 10.1921/146066909X481420. @ w\&b 
Barefoot Tutors? Student, university and field in social work education

developed an exploration of the interface between education and counselling/psychotherapy by examining the interpersonal relationship in the facilitation of learning. Believing that learning was restricted when an individual felt insecure or unsupported, Rogers challenged the very idea that educators should teach, preferring to work from the premise that the role was that of facilitation. In itself, such activity required a certain 'way of being' in the facilitator and the creation of appropriate elements in a consciously developed learning environment (Kirschenbaum \& Henderson, 1990). In essence Rogers argues for an engagement built upon a stronger commitment to a greater levelling of power dynamics. Rogers' seminal work The Freedom to Learn has had a long reaching influence on student centred learning and the establishment of defined, key principles identified by Rogers as being fundamental to an effective learner/educator engagement, has deliberate parallels with the core conditions of genuine-ness (congruence), acceptance (unconditional positive regard) and empathic understanding which are themselves at the heart of client-centred/person -centred practices (Rogers, 1951, 1969; Mearns \& Thorne, 2004).

Paying attention to the ambience of the learning environment and being consciously attuned to the human element of the learning process, adult learning theorists have further articulated and embedded Rogers' related ideas into the culture, structure and delivery of higher education, particularly in relation to mature students (Kolb, 1984; Knowles, 1988; Schon, 1987). Consideration of psychotherapeutic influences on the processes of education has led us to identify a psychodynamic thinking which offers pertinent ideas that engage with the challenge of facilitating student learning.

\section{Guarding 'the narrow ridge'}

For our purposes, educationalist Buber (1958) and psychoanalyst Winnicott (1971) both identify the type of mutual relational aspect that might exist in the tutor and student engagement. This is the ' $\mathrm{I}-$ you' dynamic, the attentive space created which nurtures and facilitates the learning experience. Buber warns us to 'guard the narrow ridge', that precious democratic territory where we can truly meet the student at the place where they are available to a learning connection; the place of the

13 J. of Practice Teaching \& Learning 9(1) 2009, pp.5-19. DOI: 10.1921/146066909X481420. ๑ wEb 
'we'. Up to now, it has usually been assumed in practice learning that the 'we' connection takes place between the student and their practice teacher or field supervisor. Our experience challenges this, and reclaims the tutor's role in student learning wherever it takes place, in the field, for our experiment, and, as we posit now, in the classroom.

Let us imagine the scene: a new student embarks on her education and eagerly meets her tutor. In psychodynamic terms a positive transference can initially be formed, with the student projecting onto, and perhaps into, the tutor a resounding expertise, an infinite source of knowingness (McGloughlin, 1995). The student might bask in the early days of the relationship in the narcissistic position of being the 'chosen' student, the successful candidate, selected and prioritised above others. A temporary period of mutual symbiosis exists as the student engages with the early stage of social work learning and finds the tutor to be a useful source of support, knowledge and wisdom - the 'infallible' other of psychodynamic engagement. As the period of practice learning looms, there is perhaps an expectation from the academic institution that the student has now been deposited with, via the traditional banking model, the required knowledge for the practice development aspect of their training. A hiatus can then occur when the hitherto able student does not successfully, or to the required standard, integrate and apply their learning to the practice setting as expected. Academia becomes fallible, disappointment prevails and the academic institution, embodied by the tutor, becomes the 'bad object' (Goldstein \& Rinsley, 1994). The consequences may be far-reaching and can be seen in student anxiety, 'blockedness',in feeling de-skilled and an over-elevation of practice learning over that of academic.

Klein's theories on splitting advise us of the readiness of the human state to divide good and bad, useful and useless, disappointing and promising (Segal, 1992). Rather than working with this transition from university to practicum and positively promoting, naming and owning the maturity which can, and should, ensue from the acceptance of the fallibility of the 'parent' figure, there has perhaps tended to be an acceptance of the negative position, for example. 'real' learning only happens in the field thus art and science, field and classroom, town and gown are split.

It is beguiling to think of the field as it where it all comes together and it seems possible that we too may have relinquished thoughts that the relationship between tutor and student can be an intrinsic tool in

14 J. of Practice Teaching \& Learning 9(1) 2009, pp.5-19. DOI: 10.1921/146066909X481420. @ w\&b 
the educative process. Therapeutic concepts come into their own here. We can turn to such concepts as we consider that significant transitional phases leading towards maturity (arriving in university, starting placement), need to be handled with sensitivity and awareness and that at during such changes we ought to predict disorganisation rather than linear, uncomplicated progression (Baker, 2006). Have we overlooked the significance of these points of transition and for example missed the opportunity for tutors to contribute to our students' positive shift from classroom to field? At some level, we perhaps allow the guilt of failed 'parenting' to lead to an acceptance of the negative positioning ascribed to us by the disappointed student (Craib, 1994).

Baker's recent paper (2006) has helped us to develop our thinking in her identification of the stage of 'studenthood'. Usefully using the university context and the student - tutor relationship, she draws upon psychodynamic thinking to assist with an understanding of the complexities of this relational connection. We are advised to heighten our awareness of the potential function of the student-tutor relationship both in terms of how it can mirror key aspects of a student's past and inner world and hence inform our understanding of what is being experienced, but also because of how we can assertively work with this connectedness to facilitate the student's progression to practice:

... some of our difficulty in onward growth and learning is due to our defensive intolerance of states of confusion, disintegration and not knowing. (Baker, 2006, p.173)

The concept of 'circumstantial transition' refers to the generic experience of a student adapting to university life. How difficult it is therefore for many social work students who must manage the transition from class to the field whilst still coming to terms with a recent move to university, along with an adaptation to the student identity and all the losses and gains which that can involve.

Could it then be that one of the tensions and influences of any ensuing 'splitting' (academia: 'irrelevant', practice placement: 'the real world') is as a result of a lack of attention to the transitional needs of this stage of student social work development? We suggest that the student/tutor dyad is potentially the place to address this. Other key opportunities may present themselves as key turning points during the programme. These could include the beginning stages of entry into university life but 
also the more ad hoc moments such as when a student finds themself in crisis. If the tutor wishes to be a meaningful player in the educational process, then they must be prepared to engage with both the educational and the emotional content of learning.

\section{Looking ahead}

Having 'leapt' over the apparent boundary between class and field, we feel inspired to enhance the level and depth of our engagement. Freire reminds us of the potential in 'situating educational activity in the lived experience of participants' (Smith, 2000). We are now keen to grow into this learning culture by expanding and developing our 'alongsidedness' with students and to build upon the emerging findings from our project in relation to the source of creative potential inherent in the relationship between tutor and student. We are presently identifying a number of ways to continue to use the notion of academic adviser in respect of the student placement. We aim to further inform our undertaking of this role by developing our understanding of both the complexities and also the potential of the student-tutor relationship in the advancement of student integration of learning. At this stage it would seem that we are initially directed to developing our understanding of the role that we as social work educators play in this complex area and that by examining and developing our psychodynamic knowledge, awareness and conscious use of skills, we can further strengthen our educational objectives. Focusing on the relational, paying attention to the interpersonal dynamics of learning brings an extra dimension and depth to the process of integration of our students' learning. After all if a key social work skill is the ability to foster trust-based productive relationships and an awareness of the role of emotions in motivation to change and learn, then tutors have much to consider if they wish to stay relevant in the process of student integration of learning.

16 J. of Practice Teaching \& Learning 9(1) 2009, pp.5-19. DOI: 10.1921/146066909X481420. ๑ w\&b 


\section{Conclusion}

The dynamics between the key players in students' integration of learning are ripe for re-appraisal and development. Others throughout the world are investigating new ways of relating to students and developing integration of learning (Dent $\&$ Tourville, 2001; Leung et al., 2001; Ku et al., 2005). All of these projects offer inspiring models of social work education being developed in new ways; where academic tutor, student and practice teacher engage in shared dialogue to create new service delivery initiatives alongside assessed social work practice and academic learning.

In the model suggested here, we offer a contribution to this process in which the working dyad created when student and tutor engage with each other, can become a learning set which in turn powers the engine for the integration of learning. We have suggested here that this will involve the renegotiation of traditional power lines. In this light then, Freire's insights on the power of dialogue and the psychodynamic perspectives on the value of paying attention to the relationship, create an interesting combination that deserves further exploration and research.

\section{References.}

Baker, A. (2006) What else do students need? Active Learning in Higher Education, 7, 2, 171-183

Baxter Magolda, M. and King, P. (Eds.) (2004) Learning Partnerships: Theory and models of practice to educate for self authorship. Sterling, VA: Stylus

Bennet, S. and Saks, L. (2006) Field notes: A conceptual application of attachment theory and research to the social work student-field instructor supervisory relationship. Journal of Social Work Education, 42, 3, 669-681

Buber, M. (1958) I - Thou. New York: Scribners' Books

Clapton, G., Cree, V., Allan, M., Edwards, R., Forbes, R., Irwin, M., Paterson, W. and Perry, R. (2008) 'Thinking 'outside the Box': A Radical Approach to Integration of Learning for Practice', Social Work Education 27, 3, 334-340

Clapton, G. and Daly, M. (2007) Bridging the theory -practice gap: Student placement groups co-facilitated by lecturers and practice teachers. Groupwork 17, 3, 60-75

17 J. of Practice Teaching \& Learning 9(1) 2009, pp.5-19. DOI: 10.1921/146066909X481420. ๑ wE-b 
Clapton, G., Cree, V., Allan, M., Edwards, R., Forbes, R., Irwin, M., Paterson, W., and Perry, R (2006) Grasping the Nettle: Integrating Learning and Practice revisited and re-imagined. Social Work Education, 25, 6, 645-656

Clapton G. and Cree, V. (2004) Integration of Learning for Practice: A literature review, Dundee: Scottish Institute for Excellence in Social Work Education

Cooper, L., Orrell, J., and Jones, R. (1999) Audit of Experiential Work-based Learning Programs at Flinders University: A report of the Practicum Project. Adelaide, SA: Flinders University

Coulshed, V. and Orme, J. (4th ed.) (2006) Social Work Practice. Basingstoke: Palgrave MacMillan

Craib, I. (1994) The Importance of Disappointment. London: Routledge

Cree, V. and MacCauley, C. (2000) Transfer of Learning in Professional and Vocational Education. London: Routledge

Dent, T. and Tourville, A. (2001) University-community partnership: Practice learning for community revitalization. in S. Shardlow, S. and M. Doel. Learning to Practice Social Work: International perspectives. London: Jessica Kingsley

Dick, E., Headrick, D.. and Scott, M. (2002) Practice Learning for Professional Skills: A review of the literature. Edinburgh: Scottish Executive

Fook, J. (2002) Social Work: Critical theory and practice. London: Sage

Freire, P. (1972) Pedagogy of the Oppressed. Harmondsworth: Penguin

Goldstein, J. and Rinsley, D. (Eds.) (1994) Fairbairn and the Origins of Object Relations. New York: Guildford

Gourevitch, P. (Ed.) (2008) The Paris Review Interviews, Vol.3. Edinburgh: Canongate

Kellner, D. (1989) Critical Theory, Marxism and Modernity. Cambridge: Polity Press

Kirschenbaum, H. and Henderson, V. L. (Eds.) (1990) The Carl Rogers Reader. London: Constable

Knowles, M.S. (1988) The Modern Practice of Adult Education: From pedagogy to andragogy, Englewood Cliffs, NJ: Prentice Hall / Cambridge Adult Education

Kolb, D.A (1984) Experiencing Learning: Experience as the source of learning and development. Englewood Cliffs, N J Prentice Hall

Ku, H.B., Yeung, S.C., and Sung-Chan, P. (2005) Searching for a capacity building model in social work education in China. Social Work Education, $24,2,213-233$

Leung, A., Hui, S.K. and Ip, F. (2001) Integrating people and services: A practice and learning experience through field instruction. in Shardlow, S. and Doel, M., Learning to Practice Social Work: International perspectives. London: Jessica Kingsley

18 J. of Practice Teaching \& Learning 9(1) 2009, pp.5-19. DOI: 10.1921/146066909X481420. @ w\&b 
Barefoot Tutors? Student, university and field in social work education

Marsh, P. and Triseliotis, J. (1996) Readiness to Practice: Training of social workers in Scotland and their first year in work. Aldershot: Avebury

McGloughlin, B. (1995) Developing Psychodynamic Counselling. London: Sage

Mearns, D. and Thorne, B. (2004) Person Centred Counselling in Action. London. Sage

Northedge, A. (1998) A critique of Freedom to Learn. in Teaching in Higher Education: Theory and Evidence. H581 Course Reader. Milton Keynes: The Open University,

Parker, J. (2004) Effective Practice Learning for Social Work. Exeter: Learning Matters

Rea, E. (1997) How well prepared for practice are newly trained social workers? Childcare in Practice, 3 (4), 77-83

Rogers, C. R. (1951) Client-Centered Counselling, Boston: Houghton-Mifflin.

Rogers, C.R. (1969) The Freedom to Learn. Columbus, OH: Merrill-Lynch

Schon, D.A, (1987) Educating the Reflective Practitioner. San Francisco: JosseyBass

Scottish Executive (2003) Framework for Social Work Education. Edinburgh: Scottish Executive. Available at www.scotland.gov.uk

Scottish Executive (2004) Changing Lives: Report of the 21st Century Review. Edinburgh: Scottish Executive. Available at www.scotland.gov.uk

Segal, J. (1992) Melanie Klein. London: Sage

Shardlow, S. and Doel, M. (1996) Practice Learning and Teaching. Basingstoke: MacMillan

Smith, M. (2000) Martin Buber on education. The Encyclopaedia of Informal Education. Retrieved 18.4.06 http://www.infed.org/thinkers/et-buber

Stalker, K. (2003) Managing Risk and uncertainty in social work. Journal of Social Work, 3, 2, 211-233

Watson, D. and West, J. (2003) The role of the tutor in social work education: Building an emancipatory tutorial relationship. Social Work Education, 22, 2, 139-149

Watson, F., Burrows, H., and Player, C. (2002) Integrating Theory and Practice in Social Work Education. London: Jessica Kingsley

Winnicott, D.W. (1971) Therapeutic Consultations in Child Psychology. New York: Basic Books. 